\title{
Ensino superior público e privado na Paraíba nos últimos 15 anos: reflexões sobre o acesso, a permanência e a conclusão
}

\author{
Public and private higher education in Paraiba in the last 15 years: \\ reflections on access, permanence and conclusion
}

\author{
Uyguaciara Veloso Castelo Branco - Universidade Federal da Paraíba | João Pessoa | PB | \\ Brasil. E-mail: uyguaciara@ gmail.com ORCID: http://orcid.org/0000-0003-3595-1415
}

Resumo: O presente artigo consiste em um estudo de caso e objetiva estabelecer parâmetros importantes para situar o fenômeno da evasão da educação superior a partir da análise dos microdados e sinopses do Censo da Educação Superior (BRASIL, MEC/INEP, 2002-2016), tendo como foco o contexto do estado da Paraíba, envolvendo as instituições de ensino superior públicas e privadas. Para tanto, utilizou-se como base teórica a compreensão da categoria evasão feita por Silva Filho; Motejunas; Hipolito; Lobo, 2007; Almeida; Veloso, 2002; Baggi; Lopes, 2011; Castelo Branco; Jezine; Nakamura, 2015. Os dados foram sistematizados e apresentados em forma de tabelas e gráficos, analisados à luz do referencial teórico. Os resultados apontam para importantes indicadores de evasão tanto no contexto público quanto no contexto privado, na Paraíba, através das reflexões sobre os dados relativos à taxa de abandono e de conclusão de curso.

Palavras-chave: Ensino Superior. Abandono escolar. Permanência na escola.

Abstract: The present article consists of a case study and aims to establish important parameters to situate the phenomenon of higher education evasion from the analysis of the microdata and synopses of the Higher Education Census (BRAZIL, MEC / INEP, 2002-2016), focusing on the context of the state of Paraíba, involving public and private higher education institutions. For that, the theoretical basis was understood as the understanding of the evasion category made by Silva Filho; Motejunas; Hipolito; Lobo, 2007; Almeida; Veloso, 2002; Baggi; Lopes, 2011; Castelo Branco; Jezine; Nakamura, 2015. The data were systematized and presented in the form of tables and graphs, analyzed in the light of the theoretical reference. The results point to important indicators of circumvention in both the public and private contexts, in Paraíba, through reflections on data on dropout rate and course completion.

Keywords: Higher Education. School Dropout. Permanence in school.

- Recebido em: 29 de setembro de 2018 • Aprovado em: 1 de março de 2020

DOI: http://dx.doi.org/10.1590/S1414-40772020000100004

Este é um artigo publicado em acesso aberto sob uma licença Creative Commons

https://creativecommons.org/licenses/by-nc/4.0/ 


\section{Introdução}

Com a gama de estudos desenvolvidos por pesquisadores acerca da ampliação do acesso à educação superior, possibilitados pela conjuntura sócio-política vivida pelo país, pós-LDB, demonstrada claramente pelo crescimento estatístico das taxas de escolarização bruta e líquida, faz centrar o debate não mais sobre o acesso à Educação Superior, pura e simplesmente, mas sobre o acesso com garantia de permanência e formação de qualidade, trazendo à tona uma discussão que sempre foi problemática no cenário da educação, em todos os níveis: os alarmantes índices de abandono ou evasão do sistema de ensino, suas causas e consequências. Segundo RIOS-NETO; GUIMARAES; PIMENTA; MORAES (2010, p. 9), a Taxa de escolarização bruta “[...] é um refinamento da Taxa de Atendimento, pois considera no numerador matrículas efetuadas em um determinado nível de ensino e, no denominador, a população em idade adequada para cursar determinado nível.”. Complementando, a Taxa de Atendimento é definida como “[...] a taxa de frequência escolar a cada faixa etária.” (p. 8). Já a Taxa de escolarização líquida “[...] é um refinamento da Taxa de Escolarização Bruta, uma vez que considera no numerador da taxa apenas as matrículas efetuadas por indivíduos em idade adequada para cursar determinado nível de ensino." (p. 9).

Nesse sentido, entrar em um sistema de ensino, seja ele na educação básica ou superior, não é garantia de ampliação de capital cultural, social e simbólico, nem tampouco garantiria aos alunos em situação de vulnerabilidade a sua mudança de padrão social, cultural e econômico. De acordo com dados apresentados em estudos recentes (CASTELO BRANCO; JEZINE; NAKAMURA, 2015, p. 769), pode-se constatar "[...] que o sistema educacional brasileiro continua a incluir os que, historicamente, já estavam destinados a ocupar os lugares reservados a eles desde o início de sua formação acadêmica."

Embora com dados restritos a um estudo de caso sobre a Universidade Federal da Paraíba (UFPB), os resultados são preocupantes:

\footnotetext{
Analisando os números absolutos da conclusão de cursos de graduação, observamos que, apesar do aumento de vagas e da ampliação significativa do acesso às populações em situação de vulnerabilidade social e econômica, pela via das políticas afirmativas, a diplomação continua restrita ao mesmo contingente numérico anteriormente dominante da população. Nesse sentido, questiona-se: estaria havendo mesmo a tão propalada democratização do acesso ao ensino superior? É possível se falar em "políticas inclusivas"? Ou não estaríamos colaborando na geração de novas formas de exclusão, pela
} 
via do fracasso educacional, quando o sistema jamais teve a pretensão de incluir aqueles que a elite tratou de manter afastados da universidade e, agora, veem-se contemplados com uma chance de adentrar aos seus portões, sem a mínima chance de nela permanecer e diplomar-se. É patente que o aumento significativo de oferta de vagas nas IFES, possibilitado pelas políticas de expansão do Governo Federal, pode ser considerado o principal fator para a mudança do perfil do ingressante na UFPB. Porém, ao identificar isso, a gestão do sistema educacional parece não ter sido capaz de envidar esforços para sanar os enormes obstáculos para a permanência desses alunos, passando a simplesmente constatar a saída ou abandono, ou mesmo a retenção, que não logram êxito no tempo compatível para a diplomação. (CASTELO BRANCO; JEZINE; NAKAMURA, 2015, p. 769-770).

Tendo em vista a necessidade sentida em aprofundar a análise envolvendo um contexto mais amplo, qual seja o estado da Paraíba, utilizando dados do Censo da Educação Superior (BRASIL. MEC/INEP, 2002-2016), tanto as sinopses quanto recorrendo aos microdados, o presente artigo tem como objetivo ampliar a busca de parâmetros que permitam discutir e compreender o complexo fenômeno da evasão, no contexto da educação superior brasileira.

Utilizou-se a metodologia dos estudos de caso, envolvendo no universo da pesquisa, as instituições de ensino superior do Estado da Paraíba, públicas e privadas.

Foram feitas tabelas e gráficos de linhas, para apresentar os dados, dando maior visibilidade aos aspectos destacados. Os dados foram analisados à luz do referencial teórico escolhido, tendo como base estudo recente sobre a temática (CASTELO BRANCO; JEZINE; NAKAMURA, 2015), além dos textos já consagrados que trazem ampla discussão sobre a evasão, tendo como cenário a educação superior brasileira (SILVA FILHO; MOTEJUNAS; HIPOLITO; LOBO, 2007; ALMEIDA; VELOSO, 2002; BAGGI; LOPES, 2011).

\section{Retomando a discussão sobre a evasão...}

A categoria evasão é definida como toda e qualquer interrupção no ciclo de estudos (GAIOSO, 2005), sendo não apenas visto como um problema de ordem educacional, mas como um verdadeiro desperdício de recursos econômicos, social e cultural.

O fenômeno é visto como significativo e crítico tanto no âmbito público, quanto privado, uma vez que implica em perda de receita e desperdício de investimento em infraestrutura (espaço físico de salas de aula, biblioteca, equipamentos, etc.), em recursos humanos (corpo docente e técnico administrativo ocioso para atender a demanda residual e não a demanda inicialmente planejada), etc. Mas nada supera a insatisfação ou desgaste emocional dos alunos que, 
pretensamente "incluídos", terminam por serem expulsos do sistema, muitas vezes pela ausência de gestão no acompanhamento da sua vida escolar, tornando o sistema incompetente em retê-los, com sucesso no curso com o qual sonharam ou tiveram acesso. Essa ausência de gestão pode ser traduzida na constatação de que:

[...] são raríssimas as IES brasileiras que possuem um programa institucional profissionalizado de combate à evasão, com planejamento de ações, acompanhamento de resultados e coleta de experiências bem-sucedidas. (SILVA FILHO; MOTEJUNAS; HIPOLITO; LOBO, 2007, p. 642).

Em se tratando da ociosidade de vagas no sistema público, essa perda de receita é ainda mais grave porque implica em impedir o acesso de milhares de alunos que ficam fora do sistema, pela limitação de vagas oferecidas gratuitamente, aguardando outro processo seletivo para ingresso muitas vezes em faculdades privadas, enquanto sobram vagas ao longo da trajetória acadêmicas dos que ingressaram e, infelizmente, não poderão ser ocupadas por este verdadeiro exército de reserva.

Outro dado preocupante é que não há a disponibilização, nos bancos de dados oficiais, de informações sobre quantitativos de alunos que vão deixando de frequentar disciplinas, são reprovados sistematicamente ou deixam de figurar nos bancos escolares, nem muito menos um mapa sobre causas ou razões da evasão nas Instituições Federais de Ensino Superior (IFES), muito menos de suas consequências para a vida acadêmica ou para as instituições. Em lugar de se ampliarem os estudos ou discussões, perde-se um tempo enorme com discussões acerca do conceito de evasão, a partir de intermináveis critérios estatísticos ou matemáticos.

Para contribuir com a discussão sobre a temática da evasão, tomou-se, como elemento para a análise de sua definição, dois aspectos fundamentais (SILVA FILHO; MOTEJUNAS; HIPOLITO; LOBO, 2007, p. 642):

A evasão deve ser entendida sob dois aspectos similares, mas não idênticos:

1. A evasão anual média mede qual a percentagem de alunos matriculados em um sistema de ensino, em uma IES, ou em um curso que, não tendo se formado, também não se matriculou no ano seguinte (ou no semestre seguinte, se o objetivo for acompanhar o que acontece em cursos semestrais). [...]

2. A evasão total mede o número de alunos que, tendo entrado num determinado curso, IES ou sistema de ensino, não obteve o diploma ao final de um certo número de anos. É o complemento do que se chama índice de titulação. [...]. 
A partir dos quantitativos encontrados, cumpre as Instituições de Ensino Superior (IES) buscarem mapear os múltiplos fatores causais ou conjunturais para tentar solucionar o problema ou, pelo menos, mantê-lo em níveis razoáveis. Para facilitar nessa tarefa, alguns autores apontam para aspectos, como: a falta de recursos financeiros dos alunos (ZAGO, 2006), questões de ordem acadêmica, que abrangem expectativas em relação ao curso ou instituição que podem motivar ou desmotivar os alunos ou tornar a conclusão de seu curso uma prioridade ou não em sua vida (SILVA FILHO; MOTEJUNAS; HIPOLITO; LOBO, 2007). Há, ainda, um aspecto extremamente pertinente para a discussão sobre a temática:

[...] falta de aquisição de "capital cultural" ao longo da trajetória de sua vida e de seus estudos, o que não se obtém de um momento para o outro. Essa desigualdade cultural é sentida desde a educação básica, quando a maioria dos alunos inicia seus estudos em desvantagem a outros, em virtude da ausência de oportunidades que tiveram em relação ao acesso a conhecimentos diversos, desde a mais tenra idade. Reconhecer essas desigualdades deve ser o primeiro passo de uma escola de qualidade, caso contrário, haverá muitos alunos incluídos no sistema escolar, mas poucos irão realmente se apropriar do conhecimento que o processo de ensino e aprendizagem exige. A permanência do aluno na IES, portanto, também depende do suporte pedagógico disponibilizado por esta, no entanto encontramos muitas instituições particulares e públicas despreparadas para estes desafios. A implementação e o acompanhamento de políticas públicas educacionais, tendo por base a igualdade de oportunidades de acesso, é uma condição necessária, mas não é a única para que ocorra a democratização efetiva nas IES particulares para combater a evasão. (BAGGI; LOPES, 2011, p. 357).

Segundo estudos (KIRA, 1998), a evasão ou fuga do aluno, em algum momento de sua vida escolar, parece ser uma combinação entre fatores de natureza pessoal, sociocultural e econômico e não um evento de causalidade única e percebida de forma simplista. Nessa mesma linha de raciocínio, outros autores corroboram com as conclusões apresentadas por Kira (1998), apontando os mesmos fatores causais (BRAGA; PEIXOTO; BOGUTCHI, 2003).

Porém, o debate sobre evasão traz à tona a necessária discussão sobre a qualidade do ensino (em todos os seus níveis) e a necessidade de avaliá-lo, propondo a articulação, praticamente inexistente apesar das preocupações governamentais datarem de 1972 (POLYDORO, 2000, p. 45), entre avaliação institucional, análise da evasão e da retenção acadêmica e criação de indicadores de qualidade do ensino nas IES.

Historicamente, alguns autores (BAGGI; LOPES, 2011, p. 363-364) chamam para essa articulação entre evasão e avaliação institucional, contemplando causas significativas como aquelas ligadas a questões internas às IES, que possam repercutir em políticas públicas de Avaliação, Campinas; Sorocaba, SP, v. 25, n. 01, p. 52-72, mar. 2020 
permanência na educação superior. Tal dificuldade em se fazer essa articulação pode ser explicada em razão de que "[...] cada IES tem seus critérios para aferir a evasão de seus alunos e que, dentro do sistema educacional as transferências entre instituições não são rastreáveis, a coleta de dados para fins de comparação entre as IES fica comprometida" (BAGGI; LOPES, 2011, p. 364).

É proposta, ainda a distinção entre evasão de curso e evasão do sistema (BAGGI; LOPES, 2011, p. 364). A primeira como a saída do curso sem concluí-lo e a segunda, como abandono completo do aluno do ensino superior propriamente dito. Nessa mesma linha, porém com expressões diferentes, utiliza-se da definição de evasão aparente, como mobilidade de um curso para outro; e evasão real, como desistência do aluno em cursar educação superior (CARDOSO, 2008).

Alguns autores (SILVA FILHO; MOTEJUNAS; HIPOLITO; LOBO, 2007) optam por denominar a diferença entre alunos matriculados de um ano de referência em relação ao anterior como evasão anual, e como evasão total ao comparativo entre o número de alunos matriculados ingressantes, em um curso em ano específico, e o número final de alunos concluintes desse curso ao final do seu prazo padrão.

Em razão da temática e da categoria estudada estar ainda em construção, entende-se ser pertinente o diálogo entre as IES públicas e privadas, tendo o comparativo numérico aliado a um debate profícuo em relação aos desafios, ações e incertezas, a partir das contribuições teóricometodológicas apresentadas, que permitiriam um trilhar mais seguro em busca de soluções a curto, médio e longo prazo.

Nesse sentido, como ponto de partida do estudo comparativo apresentado em relação ao ensino superior paraibano, utilizou-se a definição de um indicador de evasão simplificado, construído e apresentado em estudo recente (CASTELO BRANCO; JEZINE; NAKAMURA, 2015): o cálculo do abandono (Ai), baseado no modelo desenvolvido por Silva Filho; Motejunas; Hipolito; Lobo (2007):

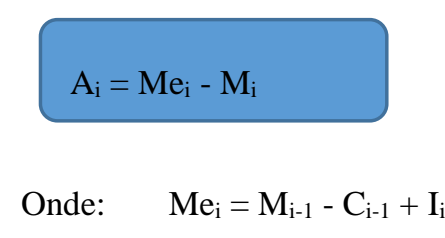

sendo:

$\mathrm{A}_{\mathrm{i}}=$ Abandono no ano $\mathrm{i}$

$\mathrm{M}_{\mathrm{i}}=$ Matrícula no ano i

$\mathrm{C}_{\mathrm{i}}=$ Concluintes no ano $\mathrm{i}$ 
Para melhor entendimento, tomou-se a definição de Ferreira, Cassiolato e Gonzalez (2009, p. 24):

O indicador é uma medida, de ordem quantitativa ou qualitativa, dotada de significado particular e utilizada para organizar e captar as informações relevantes dos elementos que compõem o objeto da observação. É um recurso metodológico que informa empiricamente sobre a evolução do aspecto observado.

O referido indicador de evasão ou Abandono (Ai) pode ser, então, definido como a diferença entre o total de matrículas esperadas (Mei) para um determinado ano e o total de matrículas efetivamente realizadas neste determinado ano. Para o cálculo da matrícula esperada (Mei), tomou-se a diferença entre o total de matrículas do ano anterior (Mi-1) e o total de concluintes do ano anterior (Ci-1), somada ao total de ingressos em determinado ano (Ii).

\section{Educação superior na Paraíba nos últimos quinze anos: um cenário complexo}

Analisando o contexto paraibano, a partir dos dados de 2002 a 2016 (último Censo disponível), na Tabela 1, a seguir, percebe-se um crescimento significativo, na Paraíba, do ensino privado em relação ao ensino público. Em termos absolutos, o ensino privado teve um aumento de 33.730 vagas no período, enquanto que o ensino público aumentou apenas 12.627 vagas, apesar do incremento significativo pós-REUNI ${ }^{1}$, a partir de 2007. Esse crescimento é da ordem de 483,2\% na rede privada e $152,2 \%$ na rede pública.

Tabela 1 - Vagas oferecidas no Ensino Superior, na Paraíba (2002-2015)

\begin{tabular}{l|r|r|r}
\hline \multirow{2}{*}{ ANO } & \multicolumn{3}{|c}{ VAGAS OFERECIDAS } \\
\cline { 2 - 4 } & Públicas & Particulares & UFPB \\
\hline 2002 & 8.294 & 6.980 & 3.434 \\
2003 & 8.327 & 9.821 & 3.457 \\
2004 & 8.852 & 13.660 & 3.617 \\
2005 & 9.156 & 14.102 & 3.436 \\
2006 & 9.612 & 14.980 & 3.612 \\
2007 & 12.595 & 15.479 & 4.407
\end{tabular}

\footnotetext{
${ }^{1}$ Programa de Apoio a Planos de Reestruturação e Expansão das Universidades Federais (REUNI), instituído pelo Decreto $n^{\circ}$ 6.096, de 24 de abril de 2007, e é uma das ações que integram o Plano de Desenvolvimento da Educação (PDE).
} 


\begin{tabular}{l|c|c|c}
\hline \multirow{2}{*}{ ANO } & \multicolumn{3}{|c}{ VAGAS OFERECIDAS } \\
\cline { 2 - 4 } & Públicas & Particulares & UFPB \\
\hline 2008 & 12.770 & 17.853 & 5.007 \\
2009 & 15.670 & 18.336 & 6.335 \\
2010 & 17.315 & 19.890 & 7.055 \\
2011 & 19.242 & 22.200 & 7.826 \\
2012 & 19.698 & 24.111 & 8.199 \\
2013 & 20.700 & 29.287 & 8.255 \\
2014 & 20.354 & 34.186 & 7.790 \\
2015 & 17.982 & 37.670 & 7.680 \\
2016 & 20.921 & 40.710 & 7.840 \\
\hline
\end{tabular}

Fonte: BRASIL. Base Censo INEP/MEC, 2002-2016.

Na UFPB (última coluna), percebe-se um elemento importante, que merece destaque: o quadro de vagas apresentado em 2002 é posterior ao desmembramento e criação da UFCG, quando foram divididos os campi, com consequente redução de vagas, cursos, recursos humanos e materiais. Face a essa conjuntura, o recorte temporal tratado nesse estudo dá conta da nova configuração da UFPB, entre 2002 e 2016, em que se percebe, como destaque, um aumento de 4.821 até 2013 (crescimento de 140,4\%), ano que teve seu pico no crescimento, havendo uma redução de 415 vagas em 2014 e mais 240 em 2015, redução essa sem explicação plausível, póstérmino do Projeto REUNI (em 2012). Essa redução afeta o comportamento de vagas públicas no mesmo ano, apesar de que se deve considerar que a queda no número de vagas em instituições públicas, em geral, é mais acentuada do que na UFPB, tomada como caso particular. Se for observado, portanto, o ano de 2016 como referência, o aumento foi de 4.406 vagas ou 128,3\%. Para uma melhor visualização, os mesmos dados são apresentados no Gráfico 1. 


\section{Gráfico 1 - Vagas oferecidas no Ensino Superior, na Paraíba (2002-2016)}

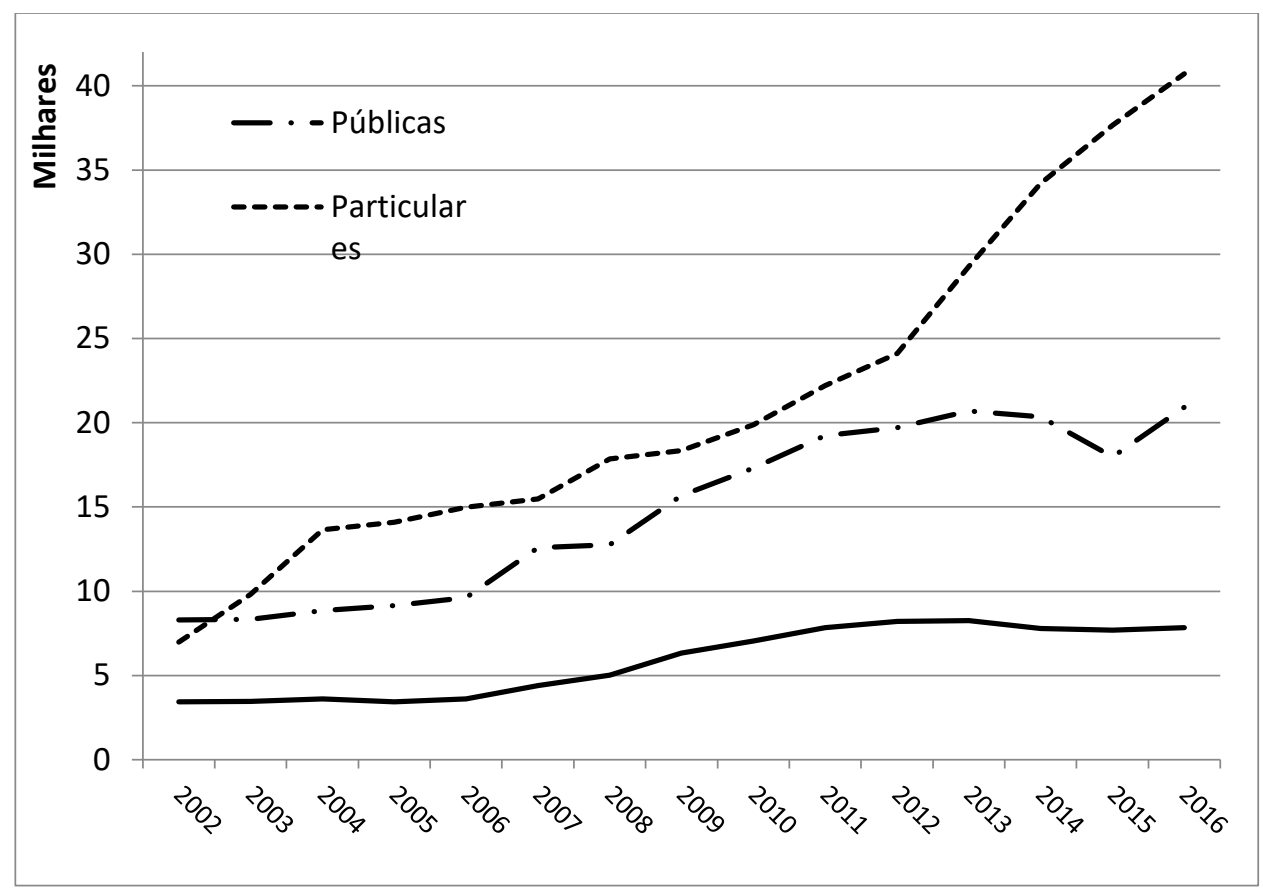

Fonte: BRASIL. INEP/MEC, 2002-2016.

Em relação aos ingressantes na educação superior, considerou-se o número total de ingressos no ensino superior no Estado da Paraíba, ou seja, por vestibular, por outro processo seletivo e outras formas de ingresso.

Na Tabela 2 e Gráfico 2, percebe-se comportamento semelhante ao observado na oferta de vagas: o ensino privado teve um aumento de 17.214 ingressantes no período de 2002 a 2014 com quedas consecutivas em 2015 e 2016, totalizando 13.033 ingressos a mais que em 2002, enquanto que o ensino público teve um aumento de apenas 9.420 alunos. Esse crescimento é da ordem de 198,5\%, na rede privada, e 98,4\%, na rede pública. Vale destacar o quantitativo de prováveis vagas ociosas no sistema privado, quando analisam-se os dados das tabelas 1 e 2 em conjunto e percebese uma "sobra" de 21.155 vagas em relação ao número de ingressantes em 2016, enquanto na rede pública esse número é de apenas 1.932 vagas "não preenchidas", apesar do programa de bolsas PROUNI e FIES, na rede privada. É importante ressaltar que as "sobras" de vagas na rede pública constituem-se em grave problema pedagógico, mas também orçamentário; na rede privada, essa "sobra" acaba servindo de "estoque" para futuros projetos de ampliação física e orçamentária, atendendo a uma lógica diferente, bastante influenciada pelo mercado, pela oferta e pela procura, 
servindo de barganha para maiores financiamentos com o suposto argumento da ampliação de acesso às camadas menos favorecidas.

Tabela 2 - Alunos Ingressos no Ensino Superior, na Paraíba (2002-2016)

\begin{tabular}{l|r|r|r}
\hline \multirow{2}{*}{ ANO } & \multicolumn{3}{|c}{ Ingressos } \\
\cline { 2 - 4 } & Públicas & Particulares & UFPB \\
\hline 2002 & 9.569 & 6.552 & 3.754 \\
2003 & 9.378 & 8.604 & 3.618 \\
2004 & 11.239 & 7.769 & 4.665 \\
2006 & 11.764 & 8.762 & 4.004 \\
2007 & 11.440 & 10.880 & 3.936 \\
2008 & 13.700 & 11.328 & 4.938 \\
2009 & 14.283 & 12.922 & 5.597 \\
2010 & 14.556 & 11.226 & 7.055 \\
2011 & 16.666 & 12.130 & 8.078 \\
2012 & 20.895 & 14.199 & 8.469 \\
2013 & 20.391 & 16.492 & 8.433 \\
2014 & 20.825 & 20.160 & 7.768 \\
2015 & 19.802 & 23.766 & 7.233 \\
2016 & 19.209 & 21.969 & 7.164 \\
\hline
\end{tabular}

Fonte: BRASIL. Base Censo INEP/MEC, 2002-2016. 


\section{Gráfico 2 - Alunos Ingressos no Ensino Superior, na Paraíba (2002-2016)}

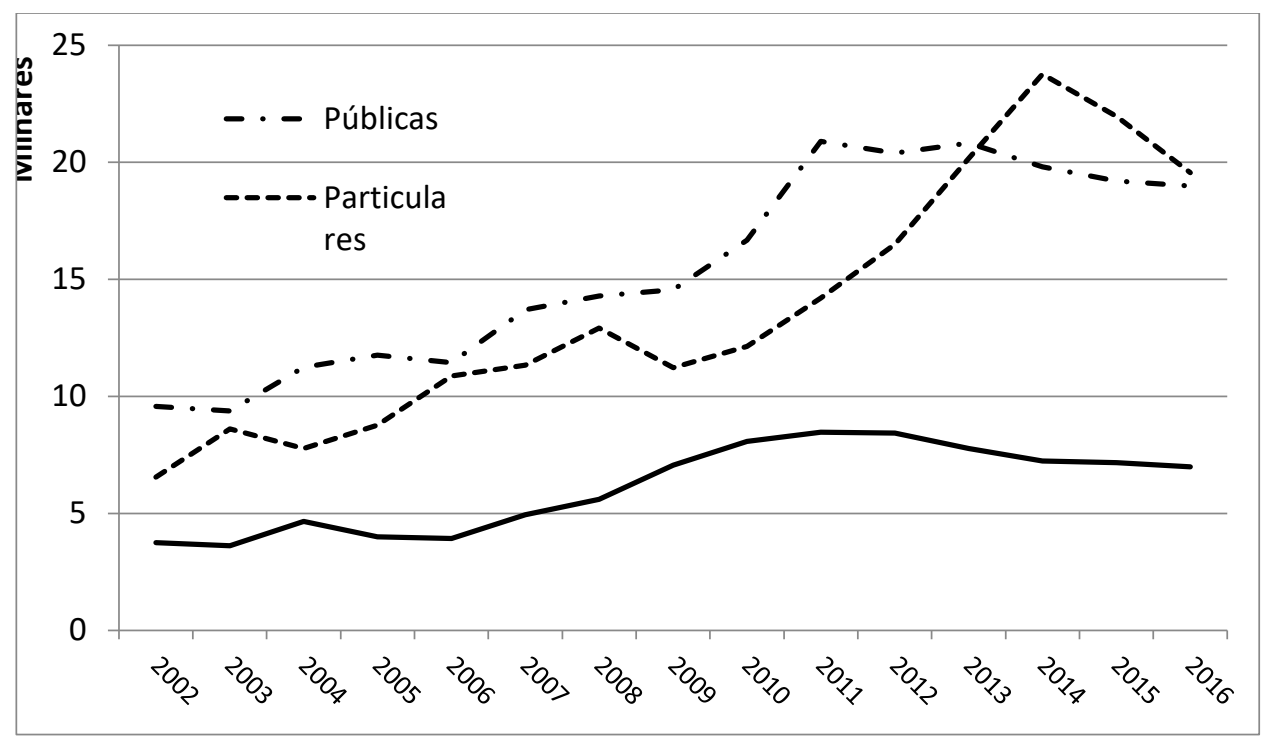

Fonte: BRASIL. Base Censo INEP/MEC, 2002-2016.

Na UFPB (última coluna), comparando o crescimento do número de ingressantes no ano de 2002 em relação a 2016, percebe-se um aumento de 3.230 ingressantes (crescimento de 86,0\%, inferior ao observado no contexto público geral), sendo acentuada a queda no número de ingressantes nos anos de 2013 a 2016, provavelmente explicadas pela adesão total da UFPB, em 2013, ao Sistema de Seleção Unificada (SISu). O ingresso pela via do SISu se caracteriza por maior mobilidade e, consequentemente, pelas múltiplas possibilidades de realização de cursos em cidades ou estados próximos ou distantes do local de origem do aluno, implicando em desistência após a aprovação, caso esta não seja vista como adequada às condições ou desejos dos alunos, com consequente diminuição do número de ingressantes nas IES.

Comparando 2012 e 2013, observa-se a perda de 665 alunos ingressantes; esse dado é ainda mais preocupante se forem comparados os anos de 2012 e 2016, com queda em 1.449 ingressantes, apontando para aumento de "vagas ociosas", na rede pública, analisando a relação entre vagas e ingressos no sistema no mesmo período.

A seguir, são apresentados, na Tabela 3 e Gráfico 3, os dados relativos à matrícula no Ensino Superior, no contexto paraibano. É importante perceber, inicialmente, que o total de matriculados representa os alunos que, efetivamente, permanecem nos sistemas de ensino, somando-se os ingressantes em cada ano com o total existente nas IES. 
Tabela 3 - Alunos Matriculados no Ensino Superior, na Paraíba (2002-2016)

\begin{tabular}{l|c|c|c}
\hline \multirow{2}{*}{ ANO } & \multicolumn{3}{|c}{ Matriculados } \\
\cline { 2 - 4 } & Públicas & Particulares & UFPB \\
\hline 2002 & 33.618 & 13.882 & 15.319 \\
2003 & 36.240 & 16.418 & 14.658 \\
2004 & 36.044 & 16.589 & 15.461 \\
2005 & 37.816 & 19.799 & 15.388 \\
2006 & 38.788 & 23.480 & 15.656 \\
2007 & 42.763 & 26.960 & 16.296 \\
2008 & 45.282 & 30.733 & 17.467 \\
2009 & 44.834 & 32.995 & 21.636 \\
2010 & 53.036 & 35.870 & 24.263 \\
2011 & 62.328 & 39.319 & 26.069 \\
2012 & 64.885 & 42.724 & 27.288 \\
2013 & 65.770 & 51.333 & 26.667 \\
2014 & 68.789 & 59.056 & 27.847 \\
2015 & 70.469 & 65.861 & 28.300 \\
2016 & 69.974 & 66.242 & 27.255 \\
\hline
\end{tabular}

Fonte: BRASIL. Base Censo INEP/MEC, 2002-2016.

Em relação aos matriculados na educação superior no Estado da Paraíba, percebe-se alguns aspectos merecedores de destaque: o ensino privado teve um aumento de 52.360 matriculados no período (2002-2016); o ensino público teve um aumento de 36.356 alunos matriculados no mesmo período; na UFPB, o aumento no período de 2002 a 2016 foi de 11.936 matriculados. Esse crescimento corresponde a $377,2 \%$ na rede privada; $108,1 \%$ na rede pública; e $77,9 \%$ na UFPB, inferior ao contexto da rede pública no Estado. Essa tendência de crescimento é melhor explicitada no Gráfico 3, seguinte. 


\section{Gráfico 3 - Alunos Matriculados no Ensino Superior, na Paraíba (2002-2016)}

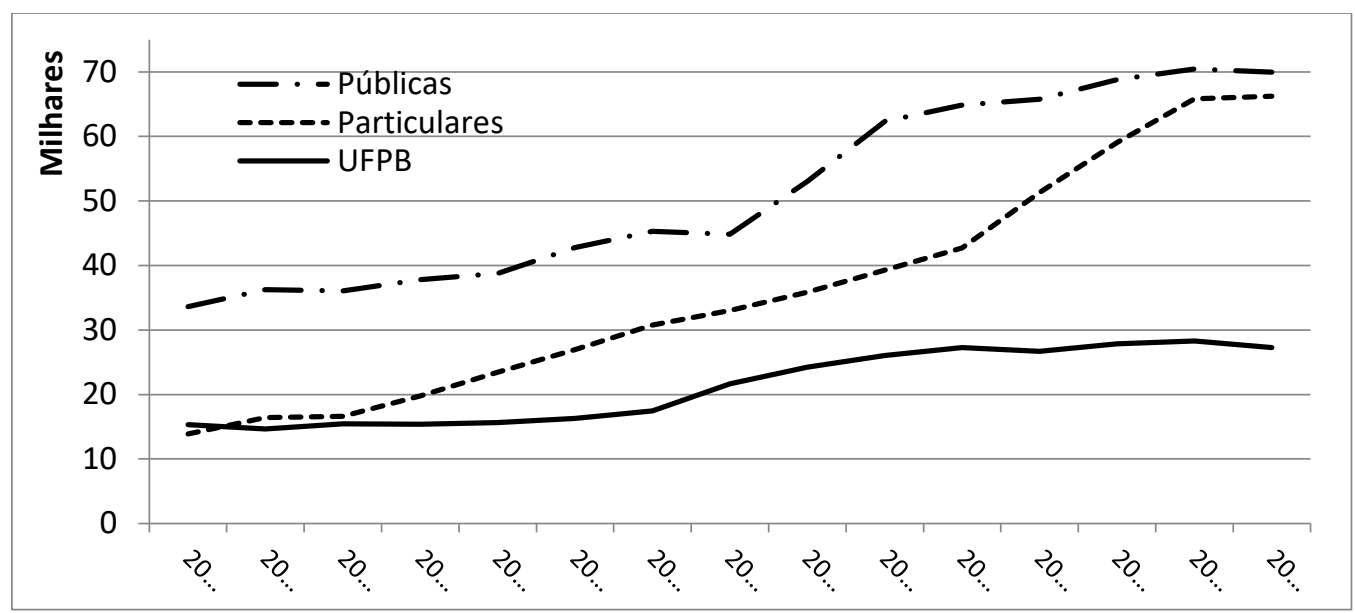

Fonte: BRASIL. Base Censo INEP/MEC, 2002-2016.

Em relação aos concluintes na educação superior, na Paraíba, na Tabela 4 e Gráfico 4, destaca-se o aumento dos concluintes tanto no ensino privado quanto no ensino público, no período estudado (2002-2016): na rede privada, o aumento foi de 8.027 (488,6\%); o ensino público teve um aumento de 5.844 concluintes (137,9\%). Na UFPB (2002-2016), o aumento foi de 2.130 concluintes $(109,2 \%)$.

Importante observar, na Tabela 4 e no Gráfico 4, que os dados relativos à Taxa de Conclusão (TC) são calculados, tendo quatro (04) anos como média de conclusão de cursos de graduação, segundo recomendações do Projeto $\mathrm{REUNI}^{2}$. A fórmula aplicada para o cálculo da TC é igual ao Total de Concluintes no ano i dividido pelo Total de Ingressos quatro anos antes do ano i, multiplicado por 100, conforme apresentado a seguir:

\section{$\mathrm{TC}_{\mathrm{i}}=\left(\mathrm{C}_{\mathrm{i}} / \mathrm{I}_{\mathrm{i}-4}\right) * 100$}

sendo:

$\mathrm{C}_{\mathrm{i}}=$ Concluintes no ano $\mathrm{i}$

\footnotetext{
${ }^{2}$ Por esse motivo, os dados da TC são apresentados a partir de 2005, tomando o ano de 2002 como referência para os quatro anos seguintes (ou seja, 2005).
} 
Tabela 4 - Alunos Concluintes no Ensino Superior, na Paraíba (2002-2016)

\begin{tabular}{l|l|l|l|l|l|l}
\hline \multirow{2}{*}{ ANO } & \multicolumn{2}{|c|}{ Públicas } & \multicolumn{2}{c|}{ Particulares } & \multicolumn{2}{c}{ UFPB } \\
\cline { 2 - 7 } & $\mathrm{N}^{\mathrm{o}}$ & $\mathrm{TC}$ & $\mathrm{N}^{\mathrm{o}}$ & $\mathrm{TC}$ & $\mathrm{N}^{\mathrm{o}}$ & $\mathrm{TC}$ \\
\hline 2002 & 4.238 & -- & 1.643 & -- & 1.950 & -- \\
2003 & 4.648 & -- & 2.134 & -- & 2.177 & -- \\
2004 & 4.524 & -- & 2.252 & -- & 2.181 & -- \\
2005 & 4.536 & 47,40 & 2.504 & 38,22 & 2.097 & 55,86 \\
2006 & 4.664 & 49,73 & 3.317 & 38,55 & 2.164 & 59,81 \\
2007 & 5.204 & 46,30 & 3.715 & 47,82 & 2.170 & 46,52 \\
2008 & 5.211 & 44,30 & 3.591 & 40,98 & 2.206 & 55,09 \\
2009 & 4.302 & 37,60 & 3.713 & 34,13 & 2.649 & 67,30 \\
2010 & 4.939 & 36,05 & 4.882 & 43,10 & 2.189 & 44,33 \\
2011 & 6.859 & 48,02 & 5.045 & 39,04 & 2.451 & 43,79 \\
2012 & 5.815 & 39,95 & 5.855 & 52,16 & 2.430 & 34,44 \\
2013 & 6.384 & 38,31 & 6.054 & 49,91 & 2.674 & 33,10 \\
2014 & 7.141 & 34,18 & 4.856 & 34,20 & 3.254 & 38,42 \\
2015 & 7.781 & 38,16 & 5.933 & 35,98 & 3.255 & 38,60 \\
2016 & 10.082 & 48,41 & 9.670 & 47,97 & 4.080 & 52,52 \\
\hline
\end{tabular}

Fonte: BRASIL. Base Censo INEP/MEC, 2002-2016.

Os dados referentes à Taxa de Conclusão (TC) mostram um pequeno crescimento da taxa na rede pública (cerca de 1\%) no período (2005 a 2016), acompanhado de um significativo crescimento na rede privada $(9,75 \%)$, apontando para uma seletividade interna ao sistema, que parece impor mecanismos de seleção ao longo do curso, sobretudo nas IES públicas, dificultando a diplomação de seus alunos, ao passo que, na rede privada, a conclusão é consequência quase esperada para a imensa maioria dos que ingressam. Porém, calculando-se a Taxa Média de Conclusão, no mesmo período, os dados apontam para percentuais muito semelhantes, ou seja, 42,4\%, 41,8\% e 47,5\%, respectivamente para a rede pública, privada e UFPB, ou seja, a UFPB, em média, tem uma TC ligeiramente superior.

Observando-se os dados ano a ano, percebe-se uma mudança significativa no ano de 2014, na rede privada, com uma queda significativa no número de concluintes, que representou em números absolutos uma redução de 1.198 alunos em relação ao ano anterior, o que pode indicar uma redução das bolsas de financiamento ou das políticas de assistência para os alunos que 
ingressam na rede privada superior. Essa queda, embora menos acentuada, também ocorreu na rede pública, ficando ambas as redes com a TC de 34\%. A mesma interseção ocorre em 2007, quando as redes pública, privada e a UFPB, em particular, atingem percentuais em torno de $46 \%$.

Na UFPB, observa-se uma oscilação bastante significativa na TC, sendo o ano de 2016 o que apresenta taxa compatível com as verificadas em seus melhores momentos, quando supera os 50\%. Entretanto, é destaque o ano de 2009 quando a TC atinge 67,3\%, talvez como resultado do reduzido número de ingressantes em 2006, com incrementos significativos de ingressantes pósREUNI (2007 e 2008), com cursos de duração reduzida (tecnológicos) acrescidos de outras modalidades de ingressos estimuladas pelo REUNI, o que repercutiu, favoravelmente, nos percentuais observados posteriormente. $\mathrm{O}$ ano de 2014 mostra um aumento de conclusão na UFPB, como consequência da expansão sofrida no auge do período do REUNI, em 2011, refletindo-se quatro anos mais tarde (em 2014). Para melhor visualização das taxas de conclusão, tem-se os dados projetados no Gráfico 4, a seguir.

\section{Gráfico 4 - Taxa de Conclusão (TC) no Ensino Superior, na Paraíba (2005-2016)}

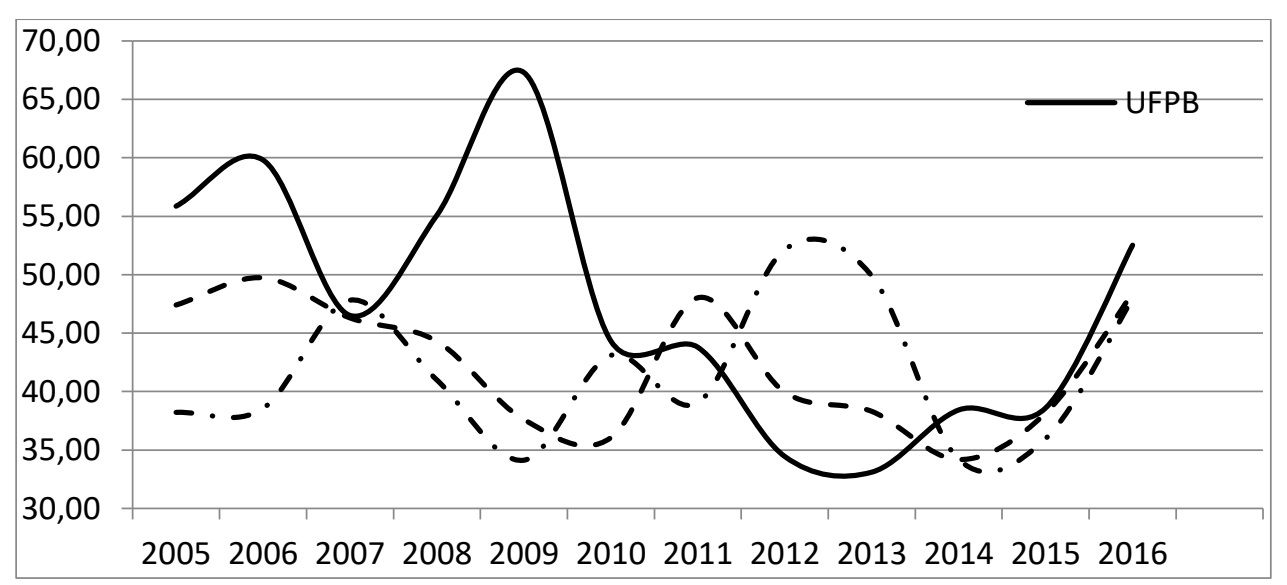

Fonte: BRASIL. Base Censo INEP/MEC, 2002-2016.

Para melhor acompanhamento do comportamento dos alunos que não concluíram o curso porém deixaram de permanecer nos sistemas de ensino, utilizou-se o modelo de cálculo do indicador de Abandono $\left(\mathrm{A}_{\mathrm{i}}=\mathrm{Me}_{\mathrm{i}}-\mathrm{M}_{\mathrm{i}}\right)$, que é a diferença entre a matrícula esperada e a matrícula efetivada no ano $i$ apresentado em Castelo Branco; Jezine; Nakamura (2015), sendo analisados os dados apresentados na Tabela 5 e Gráfico 5, a seguir, destacando-se alguns comentários relevantes: 
no mesmo período estudado anteriormente, em que houve um aumento do abandono no ensino privado paraibano; um aumento do abandono no ensino público; e um aumento do abandono na UFPB, em termos absolutos, nos anos de 2003-2016².

Os valores absolutos de abandono estão relacionados ao aumento da oferta de vagas e consequente aumento nas matrículas. Por esta razão, propõe-se relativizar o abandono em função da matrícula esperada em cada ano, denominado TA (Taxa de Abandono). Para o cálculo da Taxa de Abandono no ano i, utilizou-se a seguinte expressão:

\section{$\mathrm{TA}_{\mathrm{i}}=\left(\mathrm{A}_{\mathrm{i}} / \mathrm{Me}_{\mathrm{i}}\right) * 100$}

A Taxa de Abandono pode ser entendida, formalmente, como a proporção de matrículas esperadas que não foram realizadas efetivamente, ou seja, é o percentual de matrículas não realizadas, por fuga do sistema. Os dados referentes a este cálculo estão apresentados na tabela 5 e no Gráfico 5, a seguir.

Tabela 5 - Alunos que abandonaram o Ensino Superior, na Paraíba (2003-2016)

\begin{tabular}{l|c|c|c|c|c|c}
\hline \multirow{2}{*}{ ANO } & \multicolumn{2}{|c|}{ Públicas } & \multicolumn{2}{c|}{ Particulares } & \multicolumn{2}{c}{ UFPB } \\
\cline { 2 - 7 } & $\mathrm{N}^{\mathrm{o}}$ & $\mathrm{TA}$ & $\mathrm{N}^{\mathrm{o}}$ & $\mathrm{TA}$ & $\mathrm{N}^{\mathrm{o}}$ & $\mathrm{TA}$ \\
\hline 2003 & 2.518 & 6,50 & 4.425 & 21,23 & 2.329 & 13,71 \\
2004 & 6.787 & 15,85 & 5.464 & 24,78 & 1.685 & 9,83 \\
2005 & 5.468 & 12,63 & 3.300 & 14,29 & 1.896 & 10,97 \\
2006 & 5.932 & 13,26 & 4.695 & 16,66 & 1.571 & 9,12 \\
2007 & 5.061 & 10,58 & 4.531 & 14,39 & 2.134 & 11,58 \\
2008 & 6.560 & 12,65 & 5.434 & 15,02 & 2.256 & 11,44 \\
2009 & 9.793 & 17,93 & 5.373 & 14,00 & 680 & 3,05 \\
2010 & 4.162 & 7,28 & 5.542 & 13,38 & 2.802 & 10,35 \\
2011 & 6.664 & 9,66 & 5.868 & 12,99 & 4.474 & 14,65 \\
2012 & 10.975 & 14,47 & 8.042 & 15,84 & 4.763 & 14,86 \\
2013 & 14.125 & 17,68 & 5.696 & 9,99 & 5.959 & 18,26
\end{tabular}

${ }^{3}$ A Taxa de Abandono é calculada em relação à matrícula esperada que não foi efetivamente realizada, no ano seguinte,
daí tratar do período 2003 a 2016. Avaliação, Campinas; Sorocaba, SP, v. 25, n. 01, p. 52-72, mar. 2020 


\begin{tabular}{c|c|c|c|c|c|c}
\hline \multirow{2}{*}{ ANO } & \multicolumn{2}{|c|}{ Públicas } & \multicolumn{2}{c|}{ Particulares } & \multicolumn{2}{c}{ UFPB } \\
\cline { 2 - 7 } & $\mathrm{N}^{\mathrm{o}}$ & $\mathrm{TA}$ & $\mathrm{N}^{\circ}$ & $\mathrm{TA}$ & $\mathrm{N}^{\circ}$ & $\mathrm{TA}$ \\
\hline 2014 & 10.399 & 13,13 & 9.989 & 14,47 & 3.379 & 10,82 \\
2015 & 10.388 & 12,85 & 10.308 & 13,53 & 3.457 & 10,89 \\
2016 & 11.703 & 14,33 & 13.241 & 16,66 & 4.774 & 14,91 \\
\hline
\end{tabular}

Fonte: BRASIL. Base Censo INEP/MEC, 2002-2016.

\section{Gráfico 5 - Taxa de abandono no Ensino Superior da Paraíba (2002-2016)}

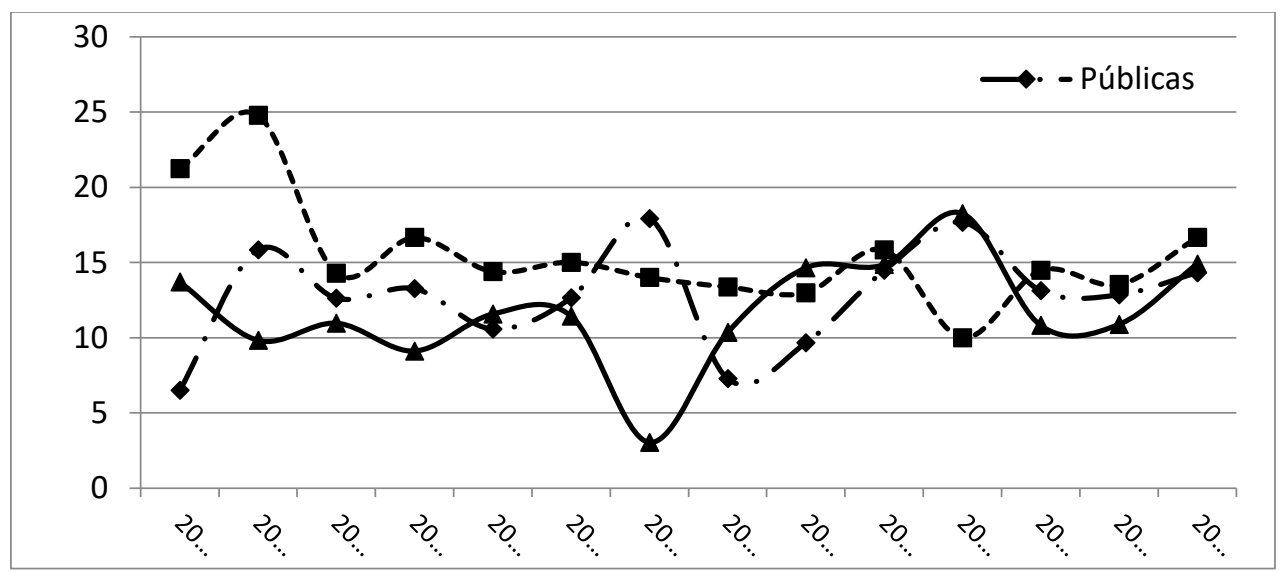

Fonte: BRASIL, Base Censo INEP/MEC, 2002-2016.

Percebe-se, pelo gráfico 5, que a Taxa de Abandono, nas redes públicas e particulares da Paraíba, comportam-se de maneira semelhante a partir de 2014.

Verifica-se, também, um ponto de interseção no ano de 2008 entre a UFPB e as demais IES públicas da Paraíba e, no ano de 2012, entre as linhas relativas à rede pública e privada da Paraíba, ocorrendo uma diminuição acentuada da Taxa de Abandono na UFPB, em 2009, e um aumento significativo, em 2013. Alguns elementos históricos podem ser identificados como explicativos ou determinantes para tal fenômeno: tem-se, na UFPB, em 2008, o maior crescimento do número de vagas pós-REUNI, quando esse gigantesco crescimento mascara o abandono por aumentar o ingresso de alunos no sistema. Já em 2012, conforme amplamente divulgado na imprensa local e nacional, teve-se uma das mais longas greves nas IFES, atingindo o patamar de mais de 100 dias 
de paralisação das aulas ${ }^{4}$, o que repercutiu em um esvaziamento do número de alunos nas IFES e, consequente, saída para as IES privadas.

Outro importante dado a ser ressaltado é que as Taxas de Abandono, apesar de permitirem melhor comparação entre os dados, possuem índices muito próximos a $15 \%$ no período, com variações entre 10 e $18 \%$ que, em números absolutos, significa a perda de mais de 10 mil alunos em cada um dos sistemas, a exemplo do que ocorre em 2016, com um quantitativo de 11.703 alunos que abandonaram o sistema público enquanto que 13.241 alunos abandonaram o sistema privado. Somando-se esses quantitativos, tem-se quase 25 mil alunos deixando a educação superior paraibana, representando um enorme desperdício de verbas e investimentos nos sistemas.

Nesse sentido, analisando-se os dados, percebe-se que o efeito das políticas de financiamento parece não ter um resultado significativo na rede privada, em que cresce, significativamente, o abandono no período estudado, sobretudo no ano de 2016, talvez explicado pela saída dos alunos com maior vulnerabilidade da rede pública (NAKAMURA; CASTELO BRANCO; JEZINE, 2013), como um entrecruzamento de sistemas que tendem a se complementar, como mostram os dados. Para que tal fenômeno pudesse ser minimizado, seria necessário, além dos programas de bolsa (PROUNI e FIES), na rede privada, e REUNI e PNAES, na rede pública, políticas eficientes de acolhimento e acompanhamento desses alunos, ao longo do percurso acadêmico, numa tentativa de mantê-los nos cursos, até a conclusão ou sucesso em sua trajetória.

\section{Considerações finais}

Os dados analisados ampliam a percepção dos pesquisadores interessados, acerca dos meandros da inclusão/exclusão, uma vez que não basta compreender as múltiplas formas de ingresso na educação superior, mas analisar, com o máximo possível de riqueza documental, os desafios da permanência e da conclusão de um curso de graduação, seja na rede pública de ensino, seja na rede privada, garantindo a qualidade na formação recebida pelos alunos, com a aquisição de capital cultural, social e econômico, levando-os ao empoderamento e transformação de suas condições de existência. Para tanto, utilizou-se, a partir da tabulação dos microdados do Censo da Educação Superior (2002-2016), a análise dos seguintes parâmetros: vagas, ingressos, matrícula,

\footnotetext{
${ }^{4}$ Para maiores detalhes, consultar: GREVE de 2012..., 2018. Ver também: APÓS quase quatro meses..., 2018; GREVES nas universidades..., 2018.
} 
taxa de conclusão e taxa de abandono, na educação superior paraibana pública, privada e, um caso particular, a UFPB.

A intenção do presente artigo é discutir as políticas públicas de acesso e permanência, na perspectiva de seus resultados efetivos nas IES públicas e privadas, e não apenas ter o encantamento possibilitado pelas estatísticas oficiais que, muitas vezes, mascaram a verdadeira face da exclusão, pela via do abandono ou evasão, tão ocultada dos documentos disponíveis dos órgãos governamentais.

O cálculo da Taxa de abandono e da Taxa de Conclusão, como elemento teóricometodológico de análise para a evasão, parece contribuir para melhor entendimento do que vem acontecendo na educação superior, apontando para a necessária revisão dos mecanismos de seleção, acompanhamento, avaliação e gestão da educação superior na Paraíba, em particular, mas no Brasil, haja vista a realidade aqui apresentada ser passível de comparação com a realidade nacional das IES.

Vislumbra-se, com esse estudo, a necessidade de aplicar os elementos teóricometodológicos aqui apresentados para ampliar as análises no contexto nacional, regional, através de estudos comparativos que enriquecerão, certamente, as reflexões dos atores envolvidos.

\section{Referências}

ALMEIDA, Edson Pacheco; VELOSO, Tereza Christina M. A. Evasão nos cursos de graduação da Universidade Federal de Mato Grosso, campus universitário de Cuiabá: um processo de exclusão. Cuiabá: UFMT. 2002.

APÓS quase quatro meses, professores de universidades federais encerram greve... Disponível em: https://educacao.uol.com.br/noticias/2012/09/16/professores-de-federais-encerramgreve.htm. Acesso em: 12 set. 2018.

BAGGI, Cristiane Aparecida dos Santos; LOPES, Doraci Alves. Evasão e Avaliação Institucional no Ensino Superior: uma discussão bibliográfica. Avaliação, Campinas; Sorocaba, SP, v. 16, n. 2, p. 355-374, jul. 2011. Disponível em: http://www.scielo.br/scielo.php?pid=S1414-

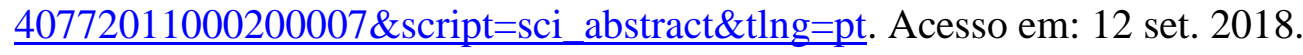

BRAGA, Mauro Mendes; PEIXOTO, Maria do Carmo L.; BOGUTCHI, Tânia F. A evasão no ensino superior brasileiro: o caso da UFMG. Avaliação, Campinas, v. 8, n. 1, p. 161-189, 2003. 
BRASIL, MEC/INEP. Censo da Educação Superior. 2002-2016. Disponível em: http://portal.inep.gov.br/web/guest/microdados. Acesso em: 21 set. 2018.

CARDOSO, Claudete Batista. Efeitos da política de cotas na Universidade de Brasília: uma análise do rendimento e da evasão. 2008. 123 p. Dissertação (Mestrado) - Universidade de Brasília, Brasília, 2008.

CASTELO BRANCO, Uyguaciara Veloso; JEZINE, Edineide; NAKAMURA, Paulo Hideo. Alguns indicadores de permanência/abandono na Educação Superior: elementos para o debate. In: SEMINÁRIO DA REDE UNIVERSITAS/BR: POLÍTICAS DE EDUCAÇÃO SUPERIOR NO BRASIL: A EXPANSÃO PRIVADO-MERCANTIL EM QUESTÃO. 23., 2015, Belém. Anais [...]. Belém/PA: UFPA, 2015.

FERREIRA, Helder; CASSIOLATO, Martha; GONZALEZ, Roberto. Uma experiência de desenvolvimento metodológico para avaliação de programas: o modelo lógico do programa segundo tempo. Texto para discussão 1369. Brasília: IPEA, 2009.

GAIOSO, Natalicia Pacheco de Lacerda. O fenômeno da evasão escolar na educação superior no Brasil. 2005. 75 f. Dissertação (Mestrado em Educação) - Programa de Pós-graduação em Educação da Universidade Católica de Brasília, Brasília, 2005.

GREVE de 2012 dos Docentes Federais passa a ser a mais longa da história do setor. Portal Sindicato Nacional dos Docentes das Instituições de Ensino Superior (ANDES-SN). Disponível em: http://www.andes.org.br:8080/andes/print-ultimas-noticias.andes?id=5576. Acesso em: 12 set. 2018.

GREVES nas universidades federais: por que sempre malsucedidas? Disponível em: http://mercadopopular.org/2017/03/universidades-federais-e-suas-greves/. Acesso em: 12 set. 2018 .

KIRA, Luci Frare. A evasão no ensino superior: o caso do curso de pedagogia da Universidade Estadual de Maringá (1992-1996). 1998. 106 f. Dissertação (Mestrado) - Programa de Pósgraduação em Educação da Universidade Metodista de Piracicaba, Piracicaba, 1998.

NAKAMURA, Paulo Hideo; CASTELO BRANCO, Uyguaciara Veloso; JEZINE, Edineide. A UFPB nos anos da expansão (2008 a 2012): quantos e quem somos e o que mudou no perfil dos nossos alunos? In: SEMINÁRIO NACIONAL UNIVERSITAS: POLÍTICAS PÚBLICAS PARA A EDUCAÇÃO SUPERIOR, EXPANSÃO E INTERNACIONALIZAÇÃO, 21., 2013, São CARLOS. Anais [...]. São Carlos: UFSCAR, 2013.

POLYDORO, Soely Aparecida Jorge. O trancamento de matrícula na trajetória acadêmica no universitário: condições de saída e de retorno à instituição. 2000. 167p. Tese (Doutorado) Universidade Estadual de Campinas, Campinas, 2000. 
RIOS-NETO, Eduardo Luiz Gonçalves; GUIMARAES, Raquel Rangel de Meireles; PIMENTA, Patrícia Silva Ferreira; MORAES, Thiago de Azevedo. Análise da evolução dos indicadores educacionais no Brasil: 1981 a 2008. Belo Horizonte: Cedeplar/UFMG, 2010.

SILVA FILHO, Roberto Leal Lobo; MOTEJUNAS, Paulo Roberto; HIPOLITO, Oscar; LOBO, Maria Beatriz de Carvalho Melo. A evasão no ensino superior brasileiro. Cadernos de Pesquisa, São Paulo, v. 37, n. 132, p. 641-659, set./dez. 2007.

ZAGO, Nadir. Do acesso a permanência no ensino superior: percursos de estudantes universitários de camadas populares. Revista Brasileira de Educação, Rio de Janeiro, v. 11, n. 32, p. 226-237, 2006. 